Original Article

\title{
Antioxidant activity of polyphenolic extract of monofloral honeybee- collected pollen from mesquite (Prosopis juliflora, Leguminosae)
}

\author{
Norma Almaraz-Abarca ${ }^{\mathrm{a}, \mathrm{b}, *}$, María da Graça Campos ${ }^{\mathrm{c}}$, José Antonio Ávila-Reyes ${ }^{\mathrm{a}, \mathrm{b}}$, \\ Nestor Naranjo-Jiménez ${ }^{\mathrm{a}, \mathrm{b}}$, Jesús Herrera Corral ${ }^{\mathrm{a}, \mathrm{b}}$, Laura Silvia González-Valdez ${ }^{\mathrm{a}, \mathrm{b}}$ \\ ${ }^{a}$ Centro Interdisciplinario de Investigación para el Desarrollo Integral Regional, Instituto Politécnico Nacional, Unidad Durango, \\ Sigma s/n 20 de Noviembre II, Durango, Dgo., México \\ ${ }^{\mathrm{b}}$ Becarios COFAA, México \\ ${ }^{\mathrm{c}}$ Laboratório de Farmacognosia, Faculdade de Farmacia, Universidade de Coimbra, 3000-295 Coimbra, Portugal
}

Received 22 September 2005; received in revised form 26 July 2006; accepted 4 August 2006

\begin{abstract}
The antioxidant capacity related to the phenolic composition of monospecific honeybee-collected pollen extract from the mesquite tree (Prosopis juliflora) from Durango, Mexico, was evaluated in an in vitro-biological system (as inhibitor of lipid peroxidation on mouse hepatic microsomal preparations) and in an in vivo system (on homogenized liver of bromobenzene-intoxicated mice) by quantification of thiobarbituric acid-reactive substances (TBARS). The comparison of results obtained from these two different systems was also made. The results obtained suggest that pollen of $P$. juliflora is an important source of flavonoids, which can be considered as natural antioxidants. Mesquite pollen extracts showed antioxidant activity related to the flavonol concentration in both the in vitro-biological system and the in vivo system with a lower activity in the latter of these systems. Under in vivo conditions and in those in which a state of oxidation in not induced, a high concentration of flavonols in the extract of mesquite pollen can have a pro-oxidant effect.
\end{abstract}

(C) 2006 Elsevier Inc. All rights reserved.

Keywords: Prosopis juliflora; Mesquite; Honeybee-collected pollen; Phenolic profiles; Antioxidant capacity

\section{Introduction}

The mesquite tree, Prosopis juliflora, is an important plant species in arid zones. It is an important species for its high nitrogen-fixing potential in very dry areas and in drought seasons, and provides shelter and food to many species of animals which feed on its nectar, pollen, leaves and fruits (Golubov et al., 2001). P. juliflora represents practically the only source of nectar and pollen to bees in April and May in several of the arid and semi-arid zones of

Abbreviations: MDA, malondialdehyde; TBA, thiobarbituric acid; TBARS, thiobarbituric acid-reactive substances

*Corresponding author. Centro Interdisciplinario de Investigación para el Desarrollo Integral Regional, Instituto Politécnico Nacional, Unidad Durango, Sigma s/n 20 de Noviembre II, Durango, Dgo., México, México. Tel./fax: + 526188142091.

E-mail address: nalmaraz@ipn.mx (N. Almaraz-Abarca).
Durango, Mexico. This fact is of relevance to beekeepers because the honey obtained acquires a uniform flavor. In the same way, the pollen gathered by the bees during these months is monospecific to mesquite.

The mesquite is an important source of natural products with biological properties (Misra, 1981; Malhotra and Misra, 1981; Nakano et al., 2004; Choundhary et al., 2005). Evaluations of the in vitro antioxidant activity of ethanolic extracts of pollen of $P$. juliflora suggest that this pollen is a substance with a high free radical scavenging activity that is related to its phenolic composition (AlmarazAbarca et al., 2003).

The phenolic composition of pollen principally consists of flavonol glycosides (Wiermann and Vieth, 1983) and of hydroxycinnamic acids (Campos, 1997). This composition tends to be species-specific (Campos, 1997; Campos et al., 1997a, b; Campos et al., 2003; Almaraz-Abarca et al., 2004), 
and has been related to the therapeutic properties (antibiotic, antineoplasic, antidiarrhoeic and antioxidant) of pollen (Campos, 1997).

It is known that the evaluations of the antioxidant activity in chemical or in in vitro-biological systems do not represent real activity in vivo (Zhang and Shen, 1997). The purpose of the present study was to determine the antioxidant capacity related to the phenolic composition of monospecific honeybee-collected pollen of $P$. juliflora from Durango, Mexico, in an in vitro-biological system (as inhibitor of lipid peroxidation on mouse hepatic microsomal preparations) and in an in vivo system (on homogenized liver of bromobenzene-intoxicated mice) by quantification of thiobarbituric acid-reactive substances (TBARS), and to compare the results obtained from these different systems.

\section{Materials and methods}

\subsection{Pollen samples}

Three samples of monospecific honeybee-collected pollen of $P$. juliflora were provided by local beekeepers expressly for this research. These samples represent the collection from San Juan del Río, Durango, Mexico, harvested in April 2002. Pollen from the anthers of flowers of mesquite was collected from trees growing in the surroundings of the beehives. The voucher specimens were placed in the Herbarium of the Centro Interdisciplinario de Investigación para el Desarrollo Integral Regional (CIIDIR) and they were identified by Socorro González, herbarium botanist.

\subsection{Microscopic examination}

Fifteen pollen pellets from each sample of monospecific honeybee-collected pollen and five samples of anther pollen were individually submitted to microscopic examination to define the botanical origin and homogeneity of the honeybee-collected pollen. Pollen samples were previously acetolyzed (Erdtman, 1966). An Olympus BX 40 microscope was used.

\section{3. $H P L C / D A D$ analysis}

To determine the flavonol/phenolic acid profile and to confirm the botanical origin of the honeybee-collected pollen by direct comparison of the high-performance liquid chromatography/diode array detector (HPLC/DAD) phenolic profiles with those of pollen collected from anthers, as has been proposed by other authors (Campos et al., 1997a, b; Almaraz-Abarca et al., 2004), single pellets of the honeybee-collected pollen were extracted with ethanolwater $(50 \% \mathrm{v} / \mathrm{v} ; 1 \mathrm{~mL})$ and sonicated for $60 \mathrm{~min}$. The resultant mixtures were centrifuged $(15269 \mathrm{~g})$ for $10 \mathrm{~min}$ and the supernatants were used for HPLC/DAD analysis as previously described (Campos, 1997). Extracts $(20 \mu \mathrm{L})$ were analyzed on a Gylson 305 HPLC system, UV detector Gylson 170 and Waters Spherisorb S50D52 $(5 \mu \mathrm{m})$ column $(4.6 \times 250 \mathrm{~mm})$ by an acidified acetonitrile-water gradient. Standard chromatograms were plotted at $340 \mathrm{~nm}$. Spectral data for all peaks were accumulated in the range 220-400 nm using DAD. Samples of pollen collected directly from anthers were analyzed in the same manner. The structural identifications were made according to Campos and Markham (2006, in press).

\subsection{Preparation of extract}

After the homogeneity of the pollen grains, the identical phenol composition and the botanical origin of honeybeecollected pollen samples were corroborated, as described above in Sections 2.2 and 2.3, extract was prepared. Twenty grams of pollen pellets were extracted five times in $200 \mathrm{~mL}$ ethanol-water solution $(50 \% \mathrm{v} / \mathrm{v})$ with 60 min maceration. The extracts were separated by centrifugation $(15269 \mathrm{~g})$ for $10 \mathrm{~min}$. All the supernatants were combined and formed the total extract; this was evaporated to dryness at low-pressure. The total extract was resolved in $10 \mathrm{~mL}$ ethanol-water solution $(50 \%, \mathrm{v} / \mathrm{v})$; different aliquots were taken to be used in the determination of flavonol content and in the antioxidant capacity evaluations.

\subsection{Determination of flavonol content in total extract}

Flavonol content was determined according AlmarazAbarca et al. (2004) by linear regression analysis from the standard curve of quercetin $\left(1-50 \mu \mathrm{g} \mathrm{mL}^{-1}\right.$ vs. absorbance): $\mathrm{Abs}_{425 \mathrm{~nm}}=-0.00221+0.054899$ [Quercetin], correlation coefficient $r=0.9973$ and from calibration curve of total extract, made from aliquots from 1 to $400 \mu \mathrm{L} \mathrm{mL}^{-1}$ ethanol-water solution $(50 \%, \quad \mathrm{v} / \mathrm{v}) \quad$ vs. absorbance $(r=0.9989)$. The curve was registered after the addition of aluminum chloride to each aliquot. The absorbance of three independent samples of each aliquot was registered at $425 \mathrm{~nm}$. The flavonol contents were expressed in $\mu \mathrm{g}$ of quercetin equivalents per $\mathrm{mL}$ extract, according to the flavonol predominance in pollen (Campos, 1997). The addition of aluminum chloride produces bathochromic shifts in flavonols containing orthodihydroxyl groups (Mabry et al., 1970), and represents a standard procedure for reproducibility (Lauranson-Broyer and Lebreton, 1993).

\subsection{Inhibition of lipid peroxidation on mouse hepatic microsomal preparations}

Determination of inhibition of lipid peroxidation was made by quantification of TBARS by a modification of the methods used by Ohkawa et al. (1979) and Uchiyama and Mihara (1978) on mouse liver microsomal preparations. The amounts of TBA reactants were expressed in terms of the malondialdehyde (MDA) concentrations $\left(\mu \mathrm{g} \mathrm{mL}^{-1}\right)$.

The livers of CF1 mice (Instituto de Virología, México), sacrificed by neck dislocation, were washed with cold $0.9 \%$ 
$\mathrm{NaCl}$ and homogenized with cold $1.15 \% \mathrm{KCl}$ to make a $10 \%$ homogenate. Microsomal fractions were prepared according to Diczfalusy et al. (1996). Protein assay was performed on microsomal fractions by the method of Lowry (García and Vázquez, 1998). The reaction mixtures composed of $100 \mu \mathrm{L}$ microsomal suspension $(86 \mu \mathrm{g}$ of protein $\left.\mathrm{mL}^{-1}\right)$, different aliquots $(0-100 \mu \mathrm{L})$ of assay substance, $50 \mu \mathrm{L}$ of an aqueous solution of $6.95 \mathrm{mg}$ of $\mathrm{FeSO}_{4}$ and $17.62 \mathrm{mg}$ of ascorbic acid, and a variable volume of Tris- $\mathrm{HCl}$ buffer $(10 \mathrm{mM}, \mathrm{pH} 7.4)$ in such a way as to maintain a constant final volume of $500 \mu \mathrm{L}$ (Campos, 1997), were incubated at $37^{\circ} \mathrm{C}$ for $30 \mathrm{~min}$ in capped tubes. After cooling in tap water, $3 \mathrm{~mL}$ of $1 \%$ phosphoric acid and $1 \mathrm{~mL}$ of $0.6 \%$ thiobarbituric acid (TBA) aqueous solution were added to each tube. The mixtures were heated for $45 \mathrm{~min}$ in a boiling water bath. After cooling, $4 \mathrm{~mL}$ of $n$-butanol were added and mixed vigorously. The butanol phase was separated by centrifugation at $10179 \mathrm{~g}$ for $10 \mathrm{~min}$ and absorbance was measured at 535 and $520 \mathrm{~nm}$. The differences were used to evaluate the concentration of TBARS according Uchiyama and Mihara (1978), based on the MDA extinction coefficient $\left(1.56 \times 105 \mathrm{M}^{-1} \mathrm{~cm}^{-1}\right)$. Reference substances (quercetin, quercitrin and caffeic acid) were assayed at four concentrations. Lipid inhibition activities were expressed in terms of the concentration of antioxidant required to inhibit MDA formation by $50 \%$ values $\left(\mathrm{IC}_{50}\right.$ in $\left.\mu \mathrm{g} \mathrm{mL}^{-1}\right)$, calculated from MDA concentrations against the sample flavonol concentrations curves by linear regression. Three independent samples of each aliquot of assay substance were analyzed.

\subsection{Evaluation of the inhibition of lipid peroxidation in bromobenzene-intoxicated mice}

The intoxication of mice was carried out by the method described by Zhang and Shen (1997). Eighty male CF1 mice from Instituto Nacional de Virología, Mexico (19-21 g) were randomly divided into eight groups: a control group (provided with cooking oil), one group provided with $200 \mu \mathrm{L}$ of extract of honeybee-collected pollen of mesquite, flavonol concentration $C 1=$ $9.794 \mu \mathrm{g} \mathrm{mL}^{-1}$; one group provided with $200 \mu \mathrm{L}$ of extract of honeybee-collected pollen of mesquite, flavonol concentration $C 2=21.751 \mu \mathrm{g} \mathrm{mL}^{-1}$; one group provided with $200 \mu \mathrm{L}$ of vitamin E (400 UI); one group intoxicated with bromobenzene $\left(200 \mu \mathrm{L}, 94.211 \mu \mathrm{g} \mathrm{mL}^{-1}\right.$ in cooking oil); and three groups intoxicated with bromobenzene $(200 \mu \mathrm{L}$, $94.211 \mu \mathrm{g} \mathrm{mL}^{-1}$ in cooking oil) after the administration of vitamin $\mathrm{E}$ (400 UI), $C 1$ and $C 2$ extract of honeybeecollected pollen, respectively. After being starved overnight, the animals were administered orally with the antioxidants and poisoned by the oral administration of bromobenzene 30-60 min later.

The animals were sacrificed by dislocation of neck 18-22 h later. The full liver of each animal was washed with cold $0.9 \% \mathrm{NaCl}$ and homogenized with cold $1.15 \% \mathrm{KCl}$ to make a $10 \%$ homogenate. Five hundred microliters of $10 \%$ homogenate were taken for TBARS assay according to the same procedures described in Section 2.6. In order to determine the relative antioxidant efficiency of the extract of honeybee-collected pollen, vitamin $\mathrm{E}$ was used as reference. Three independent samples of each homogenate were analyzed.

\subsection{Statistical analysis}

Data were analyzed by an analysis of variance $(P \leqslant 0.05)$ and means separated by Duncan's multiple range test. The results were processed by COSTAT computer program (1982).

\section{Results and discussion}

\subsection{Microscopic examination}

Microscopic examination showed that each pellet of honeybee-collected pollen was largely homogeneous, confirming the observations of Campos et al. (1997a,b) and Almaraz-Abarca et al. (2004) who observed that pollen pellets predominantly consist of pollen grains from one species. The direct microscopic comparison between pollen pellets and pollen collected from anthers showed that the honeybee-collected pollen came from $P$. juliflora.

\subsection{HPLC/DAD analyses}

As found by other authors (Campos et al., 1997a, b; Campos et al., 2003; Almaraz-Abarca et al., 2004) the botanical origin of honeybee-collected pollen can be confirmed by direct comparison of the respective HPLC/ DAD phenolic profiles with those of the pollen collected from anthers. The phenolic profile of the honeybeecollected pollen analyzed in this study was identical to that of the pollen of the anthers of $P$. juliflora. Under the experimental condition in which HPLC profiles were obtained, patterns comprising only flavonoids and cinnamic acid derivatives were found (Table 1 ).

Pollen of $P$. juliflora contained flavonoid glycosides, especially derivatives of apigenin, quercetin, isorhamnetin and probably luteolin and genistein, which are all compounds with a broad spectrum of biological activity (Formica and Regelson, 1995; Campos, 1997; Rice-Evans, 1999).

\subsection{Protection of hepatic microsomes from lipid peroxidation in vitro}

The antioxidant activity of ethanolic extract of mesquite monospecific honeybee-collected pollen was evaluated by its capacity to inhibit lipid peroxidation in the microsomal system using TBA assay. The respective values of $\mathrm{IC}_{50}$ and those of the references (quercetin, quercitrin and caffeic acid) are listed in Table 2. In this system and under our experimental conditions, extracts of this 
Table 1

Major phenols found in pollen of anthers of Prosopis juliflora, identical to the honeybee-collected pollen samples of San Juan del Río, Durango, Mexico

\begin{tabular}{ll}
\hline Major phenols & $\begin{array}{l}\text { Retention time } \\
\text { (min) }\end{array}$ \\
\hline Apigenin derivative-7- $O$-R (flavone) & 31.00 \\
Apigenin derivative-7- $O$-R (flavone) & 32.00 \\
Apigenin derivative-7- $O$-R (flavone) & 33.00 \\
Luteolin derivative (flavone) & 35.00 \\
Flavonol glycoside & 36.70 \\
Quercetin-3-glycoside (flavonol) & 37.00 \\
Genistein glycoside (isoflavone) or dihidroquercetin & 38.68 \\
(dihidroflavonoid) & \\
Isorhamnetin-3- $O$-R (flavonol) & 39.55 \\
Isorhamnetin-3- $O$-R (flavonol) & 40.78 \\
Chalcone & 41.89 \\
Isorhamnetin-3- $O$-R (flavonol) & 42.63 \\
Cinnamic acid derivative & 53.04 \\
\hline
\end{tabular}

Table 2

$\mathrm{IC}_{50}$ of ethanolic extract of monospecific honeybee-collected pollen of Prosopis juliflora and references

\begin{tabular}{ll}
\hline Sample & $\mathrm{IC}_{50}\left(\mu \mathrm{g} \mathrm{ml}^{-1}\right)$ \\
\hline Quercitrin & $0.39 \pm 0.05$ \\
Quercetin & $0.22 \pm 0.01$ \\
Caffeic acid & $0.17 \pm 0.01$ \\
Extract & $0.07 \pm 0.002$ \\
\hline
\end{tabular}

The values represent the mean and standard deviation for three independent samples.

honeybee-collected pollen were effective inhibitors of lipid peroxidation. The antioxidant activities of extracts were higher than those shown by the references, even higher than that of quercetin, which according to Terao (1999) and Okuda (1999) is a powerful antioxidant against lipid peroxidation.

It has been proposed that the species-specific flavonoid and phenolic acid contents and profiles play a significant role in determining the particular antioxidant capacity of pollen of different botanical origin (Campos et al., 2003; Almaraz-Abarca et al., 2004). Compounds possessing reactive phenolic hydroxyl groups are endowed with an important antioxidant property in vitro (Zhang and Shen, 1997), particularly those possessing the $O$-dihydroxyl structure in $3^{\prime}$ and $4^{\prime}$ position of the $\mathrm{B}$ ring in the case of flavonoids (Rice-Evans, 1999; Terao, 1999). The luteolin and quercetin derivatives of mesquite pollen carry this condition. The antioxidant capacity as lipid peroxidation inhibitor in in vitro biological systems of mesquite honeybee-collected pollen is as high as that of pollen of Amaranthus hybridus and that of a complex mixture of honeybee-collected pollen formed by six monofloral pollens from Durango, Mexico, analyzed under similar conditions (Almaraz-Abarca et al., 2004), all of them with a particular flavonoid composition. In this way, pollens from different botanical origin and different flavonoid composition may show similar antioxidant capacities. Those of pollen of $P$. juliflora, $A$. hybridus and the complex mixture are higher than those of Rannunculus petiolaris $\left(\mathrm{IC}_{50}=0.52 \mu \mathrm{g} \mathrm{mL}^{-1}\right)$, Tagetes sp. $\left(\mathrm{IC}_{50}=2.6 \mu \mathrm{g} \mathrm{mL}^{-1}\right)$, Bidens odorata $\left(\mathrm{IC}_{50}=3.6 \mu \mathrm{g} \mathrm{mL}^{-1}\right)$, Solanum rostratum $\left(\mathrm{IC}_{50}=5.9 \mu \mathrm{g} \mathrm{mL}^{-1}\right)$ and Zea mays $\left(\mathrm{IC}_{50}=16.2 \mu \mathrm{g} \mathrm{mL}^{-1}\right)$, all of which have apicultural significance, according to the values of $\mathrm{IC}_{50}$ reported by Almaraz-Abarca et al. (2004).

\subsection{Protection of bromobenzene-intoxicated mice from liver injury in vivo}

In the present study, the hepatic content of the TBARS was assayed to detect liver injury of bromobenzeneintoxicated mice and to assess the protective effects of two different concentrations of flavonols in extract of pollen of $P$. juliflora administered orally before poisoning. The results are listed in Table 3.

The total extract at flavonol concentration $C 2$ $\left(21.751 \mu \mathrm{g} \mathrm{mL}^{-1}\right)$ administered by itself had an oxidant effect as toxic as that of the bromobenzene at the concentration analyzed in this study to damage the livers of poisoned mice, giving a concentration of MDA of 0.225 and $0.202 \mu \mathrm{g} \mathrm{mL}^{-1}$, respectively, while the values of MDA $\left(0.0107 \mu \mathrm{g} \mathrm{mL}^{-1}\right)$ obtained from the mice provided with total extract at flavonol concentration $C 1\left(9.794 \mu \mathrm{g} \mathrm{mL}^{-1}\right)$ were lower than those of the control $\left(0.129 \mu \mathrm{g} \mathrm{mL}^{-1}\right)$. These two facts suggest that in conditions in which a state of oxidation is not induced, the administration of extract of pollen of mesquite with high concentrations of flavonols can be harmful to the organism because it can itself behave as an oxidant agent, inducing liver damage and a high production of MDA. The promotion of oxidation by polyphenols has been reported under particular circumstances, such as a high concentration of transient metallic ions (Okuda, 1999). Other antioxidants like ascorbic acid may also act as a pro-oxidant in vitro and in vivo when $\mathrm{Fe}$ is present (Casalino et al., 1996). The pro-oxidant role of ascorbic acid has been observed in guinea pigs supplemented with high levels of this substance (Chen and Chang, 1978). The proposed model to explain this behavior implies that ascorbic acid promotes the release of $\mathrm{Fe}$ from biomolecules where it is loosely bonded, probably from ferritin (Kapsokefalou and Miller, 2001). However the mechanism by which the flavonoids in high concentrations, and maybe other components, of the total extract of mesquite pollen exerts its pro-oxidant effect in vivo, remains to be determined. In these systems, some other factors may be involved that affect the flavonoid role in the diminished formation of reactive oxygen species.

According to Rice-Evans (1999) the specific mode of inhibition of oxidation of phenolic compounds might relate to the direct scavenging of lipid alkoxyl and peroxyl radicals by these compounds. The apparent discrepancy between the pro-oxidative effect of high flavonoid concentration extracts of mesquite pollen when these are administered by themselves, and the antioxidant effect 
Table 3

Protection from injury of substances tested on the liver of bromobenzene-intoxicated mice

\begin{tabular}{|c|c|}
\hline Treatment & TBARS $\left(\mu \mathrm{g} \mathrm{mg}^{-1}\right.$ liver $)$ \\
\hline Mesquite pollen extract, flavonol concentration $21.751 \mu \mathrm{g} \mathrm{ml}^{-1}$ & $0.2251 \pm 0.0566 \mathrm{a}$ \\
\hline Bromobenzene-intoxícated & $0.2021 \pm 0.0397 \mathrm{ab}$ \\
\hline Bromobenzene-intoxicated and pre-administered with mesquite pollen extract, flavonol concentration $9.794 \mu \mathrm{g} \mathrm{ml}^{-1}$ & $0.1629 \pm 0.05892 \mathrm{bc}$ \\
\hline Bromobenzene-intoxicated and pre-administered with mesquite pollen extract, flavonol concentration $21.751 \mu \mathrm{gml}^{-1}$ & $0.1373 \pm 0.0653 \mathrm{c}$ \\
\hline Control & $0.1293 \pm 0.0641 \mathrm{c}$ \\
\hline Bromobenzene-intoxicated and pre-administrated with vitamin $\mathrm{E}$ & $0.0241 \pm 0.0022 \mathrm{~d}$ \\
\hline Mesquite pollen extract, flavonol concentration $9.794 \mu \mathrm{g} \mathrm{ml}^{-1}$ & $0.0107 \pm 0.0017 \mathrm{~d}$ \\
\hline Vitamin E & $0.0091 \pm 0.0017 \mathrm{~d}$ \\
\hline
\end{tabular}

The values represent the mean and standard deviation for three independent samples.

when these are administered prior to, the bromobenzene, may in the second case be due to the fact that the hydrogen donation from flavonoids to lipid alkoxyl and peroxyl radicals take priority over the mechanism by which flavonoids exert their pro-oxidative effects.

In the presence of bromobenzene, both extracts of mesquite pollen (flavonol concentration of 21.751 and $9.794 \mu \mathrm{g} \mathrm{mL}^{-1}$, respectively) showed antioxidant activity in vivo. The extract of lower flavonol concentration diminished the lipid oxidation caused by bromobenzene in intoxicated mice by $19.4 \%$, while the extract with higher flavonol concentration in similar conditions reduced it by $32.1 \%$. These results suggest a relationship between the flavonol concentration in the extracts of pollen of mesquite and their level of antioxidant activity. However, neither of the extracts reached the level showed by vitamin $\mathrm{E}$ to inhibit the lipid oxidation in vivo $(88.08 \%)$. This could be explained considering that the rate of scavenging the chaincarrying lipid peroxyl radical (LOO) ${ }^{\circ}$ of quercetin is much lower than that of vitamin E (Terao, 1999) and considering that none apparent synergic effect among the compounds of pollen extract was present. Our results differ from those of Zhang and Shen (1997), who reported that the polyphenols of tea and vitamin E appear to be comparably effective as lipid peroxidation inhibitors in vivo.

Until further research has been conducted, there are at present no other data about the evaluation of capability of lipid oxidation pollen extracts in vivo, which is the reason why it was not possible to present comparisons of the antioxidant activities among pollens of different botanical origins. However, our evaluations of the lipid inhibition capability of extracts of pollen of $P$. juliflora, using the same method of MDA-TBA, allow comparing the antioxidant capacity of pollen of this species between an in vitro biological system and an in vivo system. According to these studies, the capacity to inhibit lipid oxidation (defined as the concentration of an antioxidant substance necessary to diminish the initial concentration of MDA by $50 \%$ ) of $P$. juliflora in the first of these systems was $0.07 \mu \mathrm{g} \mathrm{mL}^{-1}$. This means that in in vitro biological systems, $0.07 \mu \mathrm{g} \mathrm{mL}^{-1}$ of flavonols in a mesquite pollen extract are required to diminish the yield of MDA by $50 \%$ with regard to a control without antioxidant, while $21.751 \mu \mathrm{g} \mathrm{mL}^{-1}$ of flavonols in an analogous extract are required to induce a reduction of only $32 \%$ in the yield of MDA in an in vivo system.

\section{Conclusion}

The ethanolic total extracts of monospecific mesquite honeybee-collected pollen have a significant activity as inhibitors of lipid peroxidation in in vivo systems, and may contribute to exogenous defense against oxidative stress, even though this activity is lower than that showed by vitamin $\mathrm{E}$ and that manifested on liver microsomal preparations in in vitro biological systems. Considering its phenol profile, mesquite pollen can be considered as an important source of natural antioxidants. The flavonols present in monospecific mesquite honeybee-collected pollen are partially responsible for this antioxidant activity, due to a correlation between the flavonol concentration and antioxidant activity. The antioxidant capacity in the in vitro biological system does not represent the real activity in vivo, and further assessments on in vivo systems are necessary. Depending on the flavonol concentration and in the absence of oxidative stress, total extracts of mesquite monospecific honeybee-collected pollen can themselves behave like oxidant substances in vivo.

\section{References}

Almaraz-Abarca, N., Delgado-Alvarado, A., Ávila-Reyes, J.A., NaranjoJiménez, N., Herrera-Corral, J., 2003. Actividad Antioxidante de Extractos de Polen de Abeja Monoespecífico de Mezquite (Prosopis sp.). En: X Congreso Internacional de Actualización Apícola. Tlaxcala, Tlax, México, pp. 43-49.

Almaraz-Abarca, N., Campos, M.G., Ávila-Reyes, J.A., NaranjoJiménez, N., Herrera-Corral, J., González-Valdez, L.S., 2004. Variability of antioxidant activity among honeybee-collected pollen of different botanical origin. Interciencia 29, 574-578.

Campos, M.G., 1997. Caracterização do polen apícola pelo seu perfil em compostos fenólicos e pesquisa de algumas actividades biológicas. Tesis de doutoramento. Universidade de Coimbra, Portugal, 317pp.

Campos, M.G., Markham, K.R., 2006. Structure information from HPLC and on-line measured absorption spectra-flavone, flavonols and phenolic acids. Coimbra University Press. Portugal, in press. 
Campos, M.G., Markham, K.R., Proença da Cunha, A., 1997a. Quality assessment of bee-pollens using flavonoid/phenolic profiles. Polyphenol Communications 96, 53-54.

Campos, M.G., Mitchel, K., Cunha, A., Markham, K., 1997b. A systematic approach to the characterisation of bee pollens via their flavonoid/phenolic profiles. Phytochemical Analyses 8, 181-185.

Campos, M.G., Webby, R.F., Markham, K.R., Mitchell, K.A., Proença da Cunha, A., 2003. Age-induced diminution of free radical scavenging capacity in bee pollens and the contribution of constituent flavonoids. Journal of Agricultural and Food Chemistry 51, 742-745.

Casalino, E., Sblano, C., Landriscina, C., 1996. A posible mecanism for initiation of lipid peroxidation by ascorbate in rat liver microsomes. International Journal of Biochemistry and Cell Biology 28, 137-149.

Chen, L.H., Chang, H.M., 1978. Effects of high level of vitamin C on tissue oxidant status of guinea pigs. International Journal of Vitamin and Nutritional Research 49, 87-91.

Choundhary, M.I., Nawaz, S.A., Haq, Z., Azim, M.K., Ghayur, M.N., Lodhi, M.A., Jalil, S., Khalid, A., Ahmed, A., Rode, B.M., Rahman, A., Gilani, A.H., Ahmad, V.V., 2005. Juliflorine: a potent natural peripheral anionic-site-binding inhibitor of acetyl-cholinesterase with calcium-channel blocking potential, a leading candidate for Alzheimer's disease therapy. Biochemical and Biophysical Research Communications 332, 1171-1179.

Diczfalusy, M.A., Björkhem, I., Einarsson, K., Alexson, S.E.H., 1996. Acyl-coenzyme A: cholesterol $O$-acyltransferase is not identical to liver microsomal carboxylesterase. Arterosclerosis, Thrombosis and Vascular Biology 16, 606-610.

Erdtman, G., 1966. Pollen Morphology and Plant Taxonomy. Angiosperm. An introduction to Palinology. Halner Publishing Company, New York, 145pp.

Formica, J.V., Regelson, W., 1995. Review of the biology of quercetin and related bioflavonoids. Food Chemistry and Toxicology 33, 1061-1080.

García, A.H., Vázquez, D.R., 1998. Cuantificación de proteínas: una revisión. BioTecnología 3, 77-88.

Golubov, J., Mandujano, M., Eguiarte, L., 2001. The paradox of mesquites (Prosopis spp.): invading species or biodiversity enhancers? Boletín de la Sociedad Botánica de México 69, 23-30.
Kapsokefalou, M., Miller, D.D., 2001. Iron loading and large doses of intravenous ascorbic acid promote lipid peroxidation in whole serum in guinea pigs. British Journal of Nutrition 85, 681-687.

Lauranson-Broyer, J., Lebreton, P., 1993. Flavonoids and morphological traits of needles, as markers of natural hybridization between Pinus uncinata Ram and Pinus sylvestris L. Biochemical Systematics and Ecology 21, 241-247.

Mabry, T.J., Markham, K.R., Thomas, M.B., 1970. The systematic identification of flavonoids. Springer, New York, 354pp.

Malhotra, S., Misra, K., 1981. 3,3'-di- $O$-methylellagic acid 4- $O$-rhamnoside from the roots of Prosopis juliflora. Phytochemistry 20, 2043-2044.

Misra, K., 1981. Two flavonoid glycosides from the bark of Prosopis juliflora. Phytochemistry 20, 339-340.

Nakano, H., Nakajima, E., Hiradate, S., Fujii, Y., Yamada, K., Shigemori, H., Hasegawa, K., 2004. Growth inhibitory alkaloids from mesquite (Prosopis juliflora (Sw) DC) leaves. Phytochemistry 65, 587-591.

Ohkawa, H., Ohishi, N., Yagi, K., 1979. Assay for lipid peroxides in animal tissues by thiobarbituric acid reaction. Analytical Biochemistry 95, 351-358.

Okuda, T., 1999. Antioxidants in herbs: polyphenols. In: Packer, L., Midori, H., Toshikazu, Y. (Eds.), Antioxidant Food Supplements in Human Health. Academic Press, USA, pp. 393-410.

Rice-Evans, C., 1999. Screening of phenolics and flavonoids for antioxidant activity. In: Packer, L., Midori, H., Toshikazu, Y. (Eds.), Antioxidant Food Supplements in Human Health. Academic Press, USA, pp. 239-253.

Terao, J., 1999. Dietary flavonoids as plasma antioxidants on lipid peroxidation: significance of metabolic conversion. In: Packer, L., Midori, H., Toshikazu, Y. (Eds.), Antioxidant Food Supplements in Human Health. Academic Press, USA, pp. 255-267.

Uchiyama, M., Mihara, M., 1978. Determination of malonaldehyde precursor in tissues by thiobarbituric acid test. Analytical Biochemistry $86,271-278$.

Wiermann, R., Vieth, K., 1983. Outer pollen wall, an important accumulation site for flavonoids. Protoplasma 118, 230-233.

Zhang, J., Shen, S., 1997. Antioxidant activities of baicalin, green tea polyphenols and alizarin in vitro and in vivo. Journal of Nutrition and Environmental Medicine 7, 79-89. 